\title{
The Role of Iron Tailing Powder in Ultra-High-Strength Concrete Subjected to Elevated Temperatures
}

\author{
Kexin Huang, ${ }^{1}$ Xindan Zhang, ${ }^{2}$ Dong Lu $\mathbb{D}^{0},{ }^{3}$ Ning Xu $\left(\mathbb{D},{ }^{4}\right.$ Yingxin Gan, ${ }^{5}$ and Xin Han ${ }^{5}$ \\ ${ }^{1}$ Xi'an University of Architecture and Technology Ande College, Xi'an 710064, China \\ ${ }^{2}$ Chang'an University Weishui Campus Chang'an Dublin Institute of International, Xi'an 710064, China \\ ${ }^{3}$ School of Materials Science and Engineering, Chang'an University, Xi'an 710064, China \\ ${ }^{4}$ School of Highway, Chang'an University, Xi'an 710064, China \\ ${ }^{5}$ Zhengping Road and Bridge Construction Co., Ltd., Xining 810000, China \\ Correspondence should be addressed to Dong Lu; dongluhit@163.com and Ning Xu; xn@chd.edu.cn
}

Received 27 December 2020; Revised 19 January 2021; Accepted 19 February 2021; Published 16 March 2021

Academic Editor: Yushi Liu

Copyright (C) 2021 Kexin Huang et al. This is an open access article distributed under the Creative Commons Attribution License, which permits unrestricted use, distribution, and reproduction in any medium, provided the original work is properly cited.

\begin{abstract}
Iron tailing powder (ITP) is considered to have the potential to replace cement to manufacture ultra-high-performance concrete (UHPC). However, the performance of UHPC with the addition of ITP after exposure to high temperatures is more complex. This investigation prepares seven UHPC formulations by introducing different contents of ITP and investigates the mechanical behavior (residual strength), bound water content, and microstructural properties (crystalline and amorphous phases, chemical structure, and morphology) of UHPC subjected to elevated temperatures. The experimental results show that the addition of ITP postpones the spalling of concrete when exposed to high temperatures. The concrete incorporating $15 \%$ ITP maintains $53.8 \%$ of its original strength at $800^{\circ} \mathrm{C}$, unlike the concrete without ITP that maintains $31.6 \%$ of its original strength. The addition of ITP increases the number of micropores/cracks in concrete and helps release the vapor pressure caused by water evaporation. The findings of this investigation highlight the potential application of ITP for future UHPC design and manufacture.
\end{abstract}

\section{Introduction}

Concrete can endure high temperatures owing to its high specific heat and low thermal conductivity [1], which, however, does not imply that its performance is not degraded at all. Its compact microstructure is susceptible to explosive spalling due to the build-up of thermal stress at approximately $100^{\circ} \mathrm{C}$ of the release of vapor $[2,3]$. Moreover, the internal physical/chemical changes of concrete at high temperatures affect its mechanical strength $[3,4]$. It has been reported that the residual strength of concrete could significantly reduce when subjected to elevated temperatures [5]. In particular, ultra-high-performance concrete (UHPC) has extremely low permeability and porosity $[6,7]$, which means that the build-up of thermal pressure that existed in the pores is extremely high. Correspondingly, the high thermal pressure could cause the concrete to explosive spalling [8]. Therefore, it is essential and urgent to address or avoid the negative impacts of elevated temperatures on the performance of concrete by taking preventive measures.

An effective approach towards improving the performance of concrete at high temperatures is the accurate selection of supplementary cementitious materials (SCMs) $[9,10]$. For instance, Karahan [11] developed a high volume (0-90\%) of fly ash/slag concrete and reported that the concrete incorporating 30\% fly ash and 50\% slag achieved the optimal performance at $800^{\circ} \mathrm{C}$. Anwar [12] found that the concrete with $20 \%$ volcanic ash behaved a higher residual strength than the Portland cement concrete. However, the residual strength of concrete deteriorated sharply at $800^{\circ} \mathrm{C}$ due to a weakened interfacial transition zone. Burciaga-Díaz and Escalante-García [13] found that the concrete containing metakaolin obtained the highest strength losses of $42 \%$, while the samples with $50 \%$ granulated blast furnace slag showed minor losses of $\sim 20 \%$. Most recently, Manjunath et al. [14] prepared alkali-activated slag concrete by 
introducing $15 \%$ activated slag and pointed out that the concrete behaved better residual strength-sustaining than the ordinary concrete at $800^{\circ} \mathrm{C}$. SCMs, especially fly ash [5], metakaolin [15], and slag [16], have recently attracted much attention due to their unique characteristics, such as the stabilization of calcium hydroxide $(\mathrm{CH})$ released by pozzolanic reaction [1]. More importantly, the high temperature is conducive to the sintering of some components in concrete containing SCMs and enhances its strength [17].

The increasing demand for SCMs and effective recycling of industrial waste has been attracting wide attention for sustainability in high-performance concrete and green concrete [18]. The use of iron tailing powder (ITP) could be considered an ideal alternative cementitious material in concrete-related applications [19], because of its abundant storage [20] and low-cost [19]. Meanwhile, the outstanding pozzolanic reactivity $[21,22]$ and the filling effect of ITP particles enable it to replace cement partially, thereby reducing the $\mathrm{CO}_{2}$ emission caused by Portland cement in concrete production. Additionally, the fine ITP particles had a large surface area, which conduces to accelerating the cement hydration and helps to generate a compact cement matrix with more calcium silicate hydrates (C-S-H gel) and less $\mathrm{CH}$ [20]. Therefore, the application of ITP in concrete is regarded as a promising way to improve its performance. Besides, silica fume, as a typical pozzolanic material, is one of the mandatory raw materials in UHPC production and has been proved to have the potential to improve the high-temperature resistance of concrete [7]. However, the combined effect of variable dosages of ITP with silica fume on mechanical and microstructural properties of UHPC at high temperatures is still not clear.

This investigation aims to investigate the combined effects of variable dosages of ITP with silica fume on the mechanical and microstructural properties of UHPC at high temperatures by (1) designing seven concrete formulations by introducing different contents of ITP (0-30\%) and constant dosage of silica fume $(20 \%)$; (2) characterizing their macro-performance by mechanical properties, residual strength, and bound water content; and (3) analyzing their microstructure properties by crystalline phases analysis, amorphous characterization, chemical structure detection, and morphology observation.

\section{Experimental}

2.1. Materials. Ordinary Portland cement, silica fume, and ITP were used to prepare the UHPC mortar. The cement was produced by Qinling Factory (Shaanxi, China), whose physical properties were tested and presented in Table 1, meeting the requirements of Chinese National Standards GB 175-2007 [23]. The ITP was obtained from iron tailings after grinding for 45 minutes. The chemical composition analysis of ITP demonstrates that it has abundant calcium and silicon phase (Table 2). Particle size distribution (Malvern Instrument, Mastersizer 3000E, UK) of the raw materials showing that the ITP powder has the finest particle size (Figure 1(a)), indicating that the introduction of ITP particles help to form dense particle packing and has the potential to improve the strength of concrete [23]. The XRD patterns of ITP are presented in Figure 1(b). The silica fume had moisture of $0.58 \%$ and a density of $2.21 \mathrm{~g} / \mathrm{cm}^{3}$.

Fine quartz sand had a maximum particle diameter of $0.80 \mathrm{~mm}$ and an apparent density of $2.542 \mathrm{~g} / \mathrm{cm}^{3}$. Polycarboxylic superplasticizer (SP) was used to adjust the fluidity of the mixture [24]. It had a water-reducing of $35 \%$ and a solid content of $30 \%$.

2.2. Mix Preparations. In this study, seven concrete formulations were mixed to investigate the combined effects of variable dosages of ITP with silica fume on the performance of UHPC mortars. It should be noted that the UHPC mortars were prepared to simulate the UHPC matrix, as recommended by Mo et al. [7]. Portland cement was substituted by ITP particles (wt. \%) to prepare UHPC mortars, as presented in Table 3. For manufacturing UHPC mortars, all dry materials, including binders and sand, were firstly mixed at a low speed of $62 \mathrm{rpm}$ for $2 \mathrm{~min}$. Subsequently, the water containing dissolved SP was poured into the mixing pot and mixed at the same speed for another $3 \mathrm{~min}$. Finally, another $5 \mathrm{~min}$ mixing was performed at a high speed of $125 \mathrm{rpm}$ until a homogeneous fresh mixture was obtained.

\subsection{Test Methods}

2.3.1. Mechanical Properties of Concrete at Room Temperature. Mechanical properties of UHPC mortars at room temperature (RT) were tested according to GB/T 17671-1999 [25]. The UHPC samples were prepared with a dimension of $40 \mathrm{~mm} \times 40 \mathrm{~mm} \times 160 \mathrm{~mm}$. A three-point bending test was adopted to identify their flexural strength, and the loading rate was $50 \mathrm{~N} / \mathrm{s}$. The final recorded value was obtained by the average of the three samples. After that, the compressive strength test of UHPC was conducted based on six broken specimens from the flexural strength test, and the average of the six reading was used to define the ultimate compressive strength.

2.3.2. Chemically Bound Water Content. The hardened cement paste specimens were obtained from the broken samples, as recommended by Han et al. [26]. The chemically bound water content of the specimen was determined as follows:

$$
\begin{aligned}
W_{\mathrm{ne}} & =\frac{\left(\left(M_{1}-M_{2}\right) / M_{1}\right)-L_{B}}{1-L_{B}}, \\
L_{B} & =F_{c} \times W_{c}+F_{\mathrm{ITP}} \times W_{\mathrm{ITP}}+F_{\mathrm{SF}} \times W_{\mathrm{SF}},
\end{aligned}
$$

where $M_{1}$ and $M_{2}$ are the weight of hardened paste subjected to $80^{\circ} \mathrm{C}$ and $1050^{\circ} \mathrm{C}(\mathrm{g})$, respectively; $F_{c}, F_{\mathrm{ITP}}$, and $F_{\mathrm{SF}}$ are the mass fractions of cement, ITP, and silica fume (\%), respectively; $W_{c}, W_{\mathrm{ITP}}$, and $W_{\mathrm{SF}}$ are the loss on ignition of cement, ITP, and silica fume (\%), respectively. 
TABLe 1: Physical properties of cement.

\begin{tabular}{|c|c|c|c|c|c|}
\hline \multicolumn{2}{|c|}{$\begin{array}{c}\text { Flexural strength } \\
(\mathrm{MPa})\end{array}$} & \multicolumn{2}{|c|}{$\begin{array}{l}\text { Compressive strength } \\
(\mathrm{MPa})\end{array}$} & \multirow[t]{2}{*}{ Specific surface area $\left(\mathrm{m}^{2} / \mathrm{kg}\right)$} & \multirow[t]{2}{*}{ Density $\left(\mathrm{g} / \mathrm{cm}^{3}\right)$} \\
\hline $3 \mathrm{~d}$ & $28 \mathrm{~d}$ & $3 \mathrm{~d}$ & $28 \mathrm{~d}$ & & \\
\hline 4.3 & 8.2 & 23.8 & 46.8 & 350 & 2.875 \\
\hline
\end{tabular}

TABLE 2: Composition analysis of raw materials (\%).

\begin{tabular}{lccccccc}
\hline Specimens & $\mathrm{CaO}$ & $\mathrm{SiO}_{2}$ & $\mathrm{Al}_{2} \mathrm{O}_{3}$ & $\mathrm{Fe}_{2} \mathrm{O}_{3}$ & $\mathrm{SO}_{3}$ & $\mathrm{MgO}$ & Loss on ignition \\
\hline Cement & 57.58 & 20.35 & 6.12 & 4.23 & 2.19 & 2.59 & 2.59 \\
Silica fume & 0.41 & 94.02 & 0.27 & 0.11 & 0.11 & 0.34 & 2.86 \\
Iron tailing powder & 12.12 & 51.85 & 11.24 & 9.34 & 0.41 & 4.86 & 2.41 \\
\hline
\end{tabular}

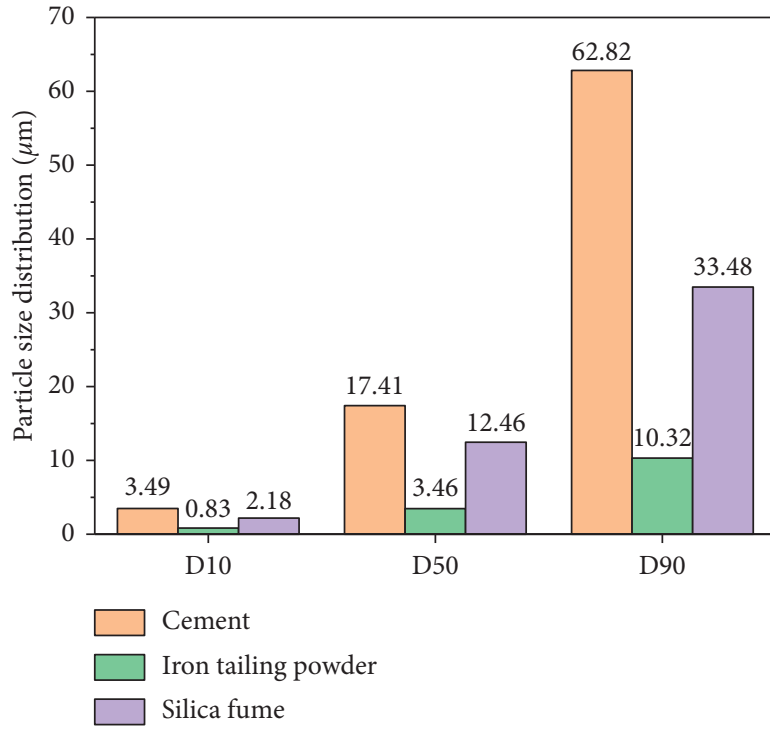

(a)

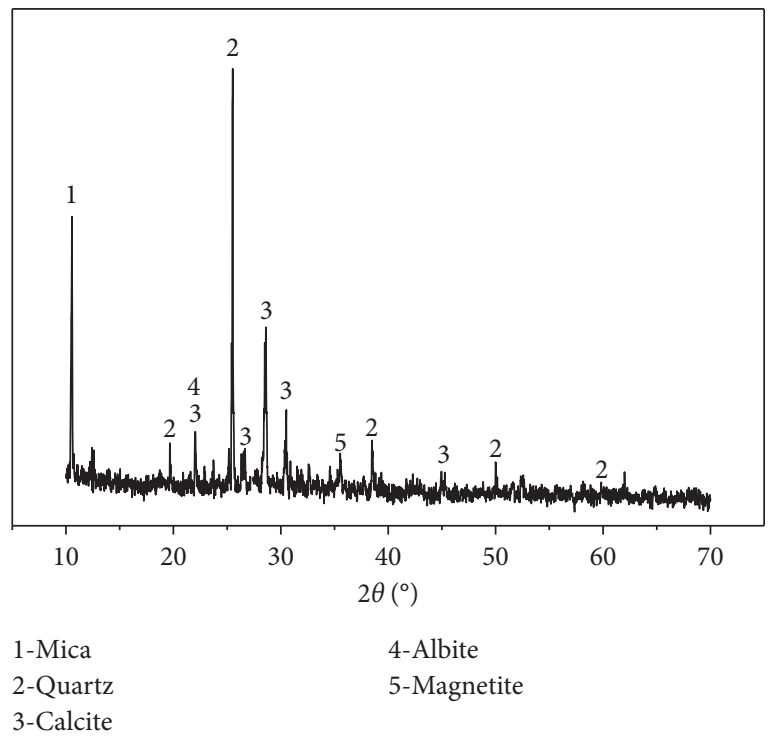

(b)

FIgURE 1: (a) The particle size distribution of raw materials and (b) the XRD patterns of iron tailing powder.

TABLE 3: Mix proportions of UHPC mortar*.

\begin{tabular}{lccccc}
\hline & \multicolumn{2}{c}{$\begin{array}{c}\text { Cement was } \\
\text { substituted by } \\
\text { ITP (wt. \%) }\end{array}$} & \multicolumn{3}{c}{$\begin{array}{c}\text { Mix proportion of concrete } \\
\left(\mathrm{kg} / \mathrm{m}^{3}\right)\end{array}$} \\
& Cement & ITP & SF & Quartz sand & SP \\
\hline CITP0 & 100 & 0 & 168 & 1330 & 21 \\
CITP5 & 95 & 5 & 168 & 1330 & 21 \\
CITP10 & 90 & 10 & 168 & 1330 & 21 \\
CITP15 & 85 & 15 & 168 & 1330 & 21 \\
CITP20 & 80 & 20 & 168 & 1330 & 21 \\
CITP25 & 75 & 25 & 168 & 1330 & 21 \\
CITP30 & 70 & 30 & 168 & 1330 & 21 \\
\hline
\end{tabular}

${ }^{*} w / b=0.37$.

2.3.3. Residual Strength Testing. Residual strengths of UHPC mortars after exposure to high temperatures were determined by residual flexural strength and residual compressive strength, as recommended by Abaeian et al. [27]. For this purpose, the UHPC specimens $(40 \mathrm{~mm} \times 40 \mathrm{~mm} \times 160 \mathrm{~mm})$ were cured in water $\left(20 \pm 3^{\circ} \mathrm{C}\right)$ until 28 days age. After that, they were placed in an oven for heating at $60^{\circ} \mathrm{C}$ for 48 hours. Subsequently, an electrically controlled furnace (KRX, Henan, China) was employed to heat the UHPC mortars from RT to the set temperature of $200^{\circ} \mathrm{C}, 400^{\circ} \mathrm{C}, 600^{\circ} \mathrm{C}$, and $800^{\circ} \mathrm{C}$, respectively, with a heating rate of $3^{\circ} \mathrm{C} /$ minute. Finally, the specimens were kept in the target temperature for another 3 hours, and then the electrically controlled furnace was turned off and naturally cooled to the ambient temperature [28].

2.3.4. Microscopic Investigation. The specimens were soaked in ethanol and sealed continuously for seven days to stop the cement hydration. After that, these specimens were dried in a vacuum oven at $60^{\circ} \mathrm{C}$ for $48 \mathrm{~h}$ before testing.

X-ray diffraction (XRD, 6000, Daojin, Japan) was adopted to analyze the constituent of UHPC after exposure to elevated temperatures. For this purpose, the dry powders $(<45 \mu \mathrm{m})$ were produced by grinding the selected crushed samples. XRD measurements were performed with $\mathrm{Cu} \mathrm{K} \alpha$ radiation $(\lambda=1.54 \AA$ ) and carried out using constant pass energy $(40 \mathrm{kV}$ and $30 \mathrm{~mA})$. The diffraction patterns were 
obtained with a scanning rate of 10 degrees $/ \mathrm{min}$ in a $2 \theta$ range of 10-70 degrees. Thermogravimetric analysis (TGA) was applied to characterize the amorphous phases of UHPC. TGA experiment was conducted using a Discovery SDT 650 thermal analyzer (TA Instruments, USA). The dry powders were tested under an oxygen atmosphere, and the heating rate was $20^{\circ} \mathrm{C} / \mathrm{min}$. Fourier-transform infrared spectrometer (FTIR, BRUKER TENSOR II, Germany) was adopted to measure the chemical structures of UHPC. For this purpose, the test powder samples $(<45 \mu \mathrm{m})$ were carried out in the wavenumber range of $400-4000 \mathrm{~cm}^{-1}$ [29].

Scanning electron microscopy (SEM, S4800, Hitachi, Japan) was adopted to explain the internal microstructure and morphology of UHPC. For this purpose, the surface of the samples was coated with Au to prevent charging effects before testing. The samples were dried under vacuum conditions, and the test voltage was $15 \mathrm{kV}$.

\section{Results and Discussion}

3.1. Compressive Strength. The compressive strength of UHPC mortars at 28 days all exceeds $120 \mathrm{MPa}$ (Figure 2(a)); it can be concluded that the addition of ITP (within 30\%) could obtain an excellent compressive strength. Moreover, the sample CITP15 reaches the highest strength value at 28 days $(148.8 \mathrm{MPa})$. The addition of ITP accelerated the hydration of cement [22] and promoted the generation of hydration products [30]. Also, the fine ITP particles filled the voids and contributed to the strength of concrete $[24,26]$.

The compressive strength of CITP30 was lower than the CITP15 sample and even lower than the reference sample CITP0. Interestingly, the compressive strength of CITP30 slightly decreased by $3.2 \%$, compared to the CITP0 at 28 days. The high substitution level of ITP adsorbed a lot of free water [18], increased the amount of unhydrated cement particles, and limited the strength formation of concrete [30]. Also, the hydration products generated by ITP were very limited due to the low reactivity as compared to the Portland cement [26].

3.2. Flexural Strength. The flexural strength of samples at 28 days all exceeds $20 \mathrm{MPa}$ (Figure 2(b)). In particular, the flexural strength of the CITP10 sample slightly increased by $7.7 \%$, compared to the sample CITP0 at 28 days. As $15 \%$ ITP was added, the flexural strength of UHPC mortars could be further increased by $26.1 \%$. Besides, the flexural strength value of the CITP30 sample dropped to $20.3 \mathrm{MPa}$, a decrease by $1.5 \%$ compared to the reference sample CITP0.

3.3. Chemically Bound Water Content. As presented in Figure 3, the CITP15 obtains the highest chemically bound water content value (17.32\%), slightly increased by $4.2 \%$ compared to the reference sample CITP0. The result was mainly because the sample CITP15 had the largest amount of C-S-H gel [19]. However, lower bound water content could be achieved in the CITP30 sample. The high replacement level of ITP (30\%) decreased the number of hydration products. These results further verified that the optimal addition of ITP was $15 \%$ in concrete production.

It can be found that there was a subtle difference in the bound water content between the UHPC mortars with and without ITP. Also, for the CITP0 sample, the bound water content was slightly higher than that of the CITP25 and CITP30 samples, but slightly lower than that of samples CITP5, CITP10, and CITP15 samples. The result was consistent with the above compressive strength (Figure 2(a)). It indicated that the addition of ITP mainly exerted the nucleation effect and the filling effect.

3.4. Residual Strength. Two obvious stages of evolution of residual strength with temperature could be observed (Figure 4). The first stage corresponds to between RT and $200^{\circ} \mathrm{C}$, and the second phase corresponds to the temperature between $200^{\circ} \mathrm{C}$ and $800^{\circ} \mathrm{C}$.

3.4.1. Residual Compressive Strength. The first stage (below $200^{\circ} \mathrm{C}$ ) shows a slight increase in residual compressive strength (Figure 4(a)). For example, the residual strength of CITP0 at $200^{\circ} \mathrm{C}$ increased by $9.7 \%$, compared with the reference sample at RT. Some cement hydrates were decomposed at $200^{\circ} \mathrm{C}$, which provided water to unhydrated cement particles that existed in capillary pores and contributed to the strength development [31]. As Portland cement was substituted by $10 \%$ ITP, the residual compressive strength increased to $149.5 \mathrm{MPa}$. Since the filling effect of ITP particles, as well as their chemical reactivity, was greatly stimulated by the high temperatures [1], some additional hydration products were generated and the denser microstructure was formed [32]. Residual compressive strength of CITP15 sample further increased to $156.3 \mathrm{MPa}$, which was caused by the outstanding filling effect of ITP. Similar conclusions pointed out that the additional amount of $\mathrm{C}-\mathrm{S}-\mathrm{H}$ gel with low $\mathrm{Ca} / \mathrm{Si}$ was generated due to the presence of amorphous aluminosilicate in ITP [33]. Interestingly, the residual compressive strength of sample CITP30 decreased to $143.9 \mathrm{MPa}$, which suggested the importance of the replacement level of ITP in concrete preparation.

In the second stage $\left(400-800^{\circ} \mathrm{C}\right)$, the residual compressive strength decreased with temperatures. The decreasing trend was roughly linear below $400^{\circ} \mathrm{C}$. In comparison, a significant drop of residual strength was observed beyond $400^{\circ} \mathrm{C}$, which was caused by the decomposition of $\mathrm{CH}$ and the desiccation of the pore system [13]. The CITP15 maintained 53.8\% of its original strength after 3 hours of annealing at $800^{\circ} \mathrm{C}$. While the CITP0 and CITP30 samples maintained $31.6 \%$ and $39.7 \%$ of their original strength, respectively. The addition of ITP significantly increased the number of micropores, microvoids, and microcracks, which helped to release the accumulated vapor pressure, thereby improving the residual strength of concrete [8]. Besides, the high strength of UHPC postponed the degradation of the microstructure caused by the free evaporation of water at high temperatures. 


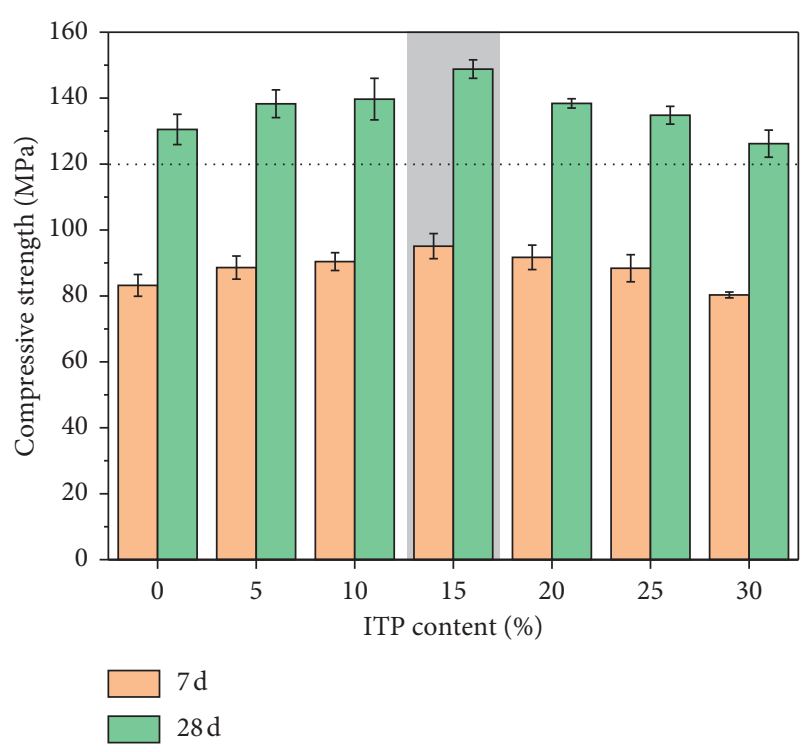

(a)

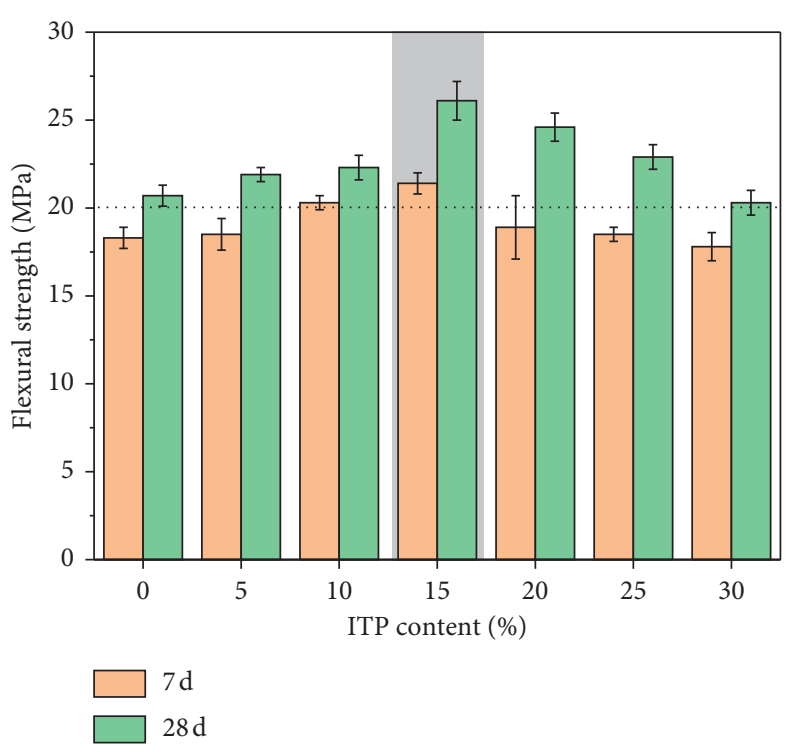

(b)

FIgURE 2: Mechanical properties of UHPC mortar: (a) compressive and (b) flexural strength.

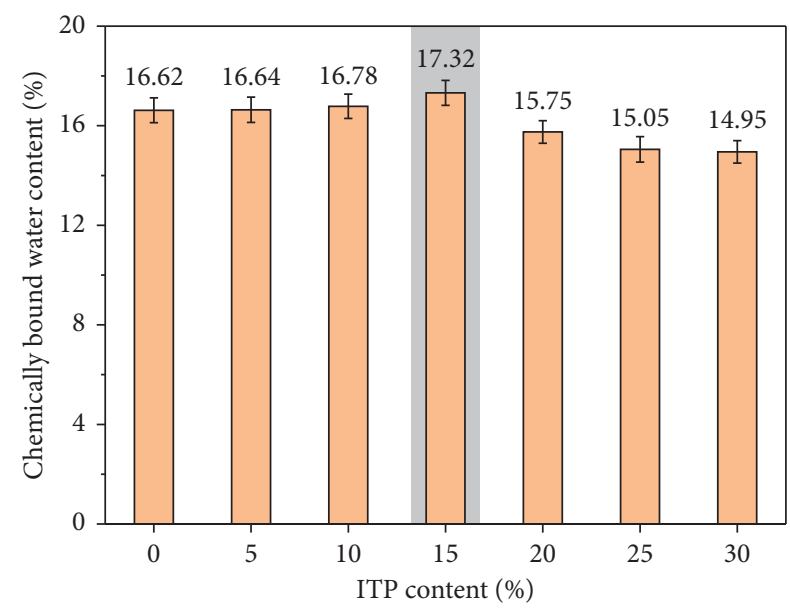

FIGURE 3: The bound water content of samples containing different contents of ITP.

3.4.2. Residual Flexural Strength. Residual flexural strength of concrete at $200^{\circ} \mathrm{C}$ increased by approximately $15 \%$, compared to the UHPC mortars at RT (Figure 4(b)). At $800^{\circ} \mathrm{C}$, the residual flexural strength of samples significantly dropped to approximately $6.7-7.1 \mathrm{MPa}$, except for the CITP15 sample, which can still retain almost $8 \mathrm{MPa}$ after 3 hours of annealing. This could also confirm that the addition of $15 \%$ ITP was most effective for improving the hightemperature resistance of concrete.

3.5. $X R D$. Typical reflections, such as portlandite $(\mathrm{CH})$, alite $\left(\mathrm{C}_{3} \mathrm{~S}\right)$, and belite $\left(\mathrm{C}_{2} \mathrm{~S}\right)$, can be observed in Figure 5. Note that, C-S-H gel cannot be found due to its amorphous phase [26], which will be analyzed in TGA and FTIR discussions (will be illustrated in Sections 3.6 and 3.7).
The diffraction peak of $\mathrm{CH}$ of CITP15 is slightly stronger than the CITP0 sample. The introduction of ITP promoted the hydration of cement particles and generated more hydration crystals [34]. While the reactivity of ITP was lower as compared to the cement. Therefore, the number of hydration products was decreased when a higher portion of cement was replaced by ITP [30]. As a result, the addition of $30 \%$ ITP limited the further hydration of cement and resulted in the reduction of strength (Figure 2). The diffraction peaks $\mathrm{C}_{2} \mathrm{~S}$ and $\mathrm{C}_{3} \mathrm{~S}$ in sample CITP 15 at $200^{\circ} \mathrm{C}$ became weaker than those of the sample CITP0 at RT. This was mainly due to some of the unhydrated cement particles that existed in the capillary pores rehydrated at $200^{\circ} \mathrm{C}$ [35]. In this process, the additional gel-like hydration products were formed [36]. The diffraction peak intensity of $\mathrm{CH}$ crystal gradually decreased at $400^{\circ} \mathrm{C}$ and disappeared at $800^{\circ} \mathrm{C}$ because the $\mathrm{CH}$ crystal began to decompose over a temperature range between $350^{\circ} \mathrm{C}$ and $600^{\circ} \mathrm{C}$ [37]. Therefore, the residual strength of concrete decreased in this stage (Figure 4).

3.6. TGA. As presented in Figure 6(a), the first absorption peak (\#1) that appears at approximately $90^{\circ} \mathrm{C}$ was mainly caused by the loss of free water and physically bound water [8]. Furthermore, a mass loss below $120^{\circ} \mathrm{C}$ was attributed to the decomposition of nearly amorphous C-S-H gel [13]. In the range of $120-200^{\circ} \mathrm{C}(\# 2)$, the mass loss was due to the dehydration of the C-S-H gel [8]. Note that, the second peak $(\# 2)$ of CITP30 was lower than the CITP0, which suggested that the CITP30 sample had less C-S-H gel content than the sample CITP0. It was attributed to the less cement consumption and the limited pozzolanic reaction of ITP. The peaks were located at about $430^{\circ} \mathrm{C}(\# 3)$ and $690^{\circ} \mathrm{C}(\# 4)$ which corresponded to dehydration of $\mathrm{CH}$ and decarbonization of $\mathrm{CaCO}_{3}$ [13], respectively. The $\mathrm{CH}$ content in the CITP15 


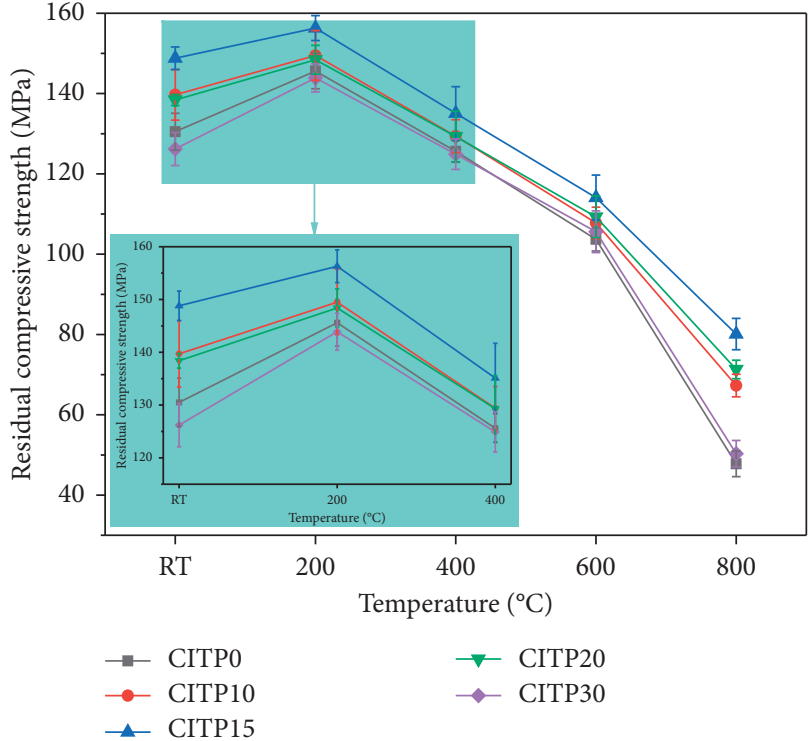

(a)

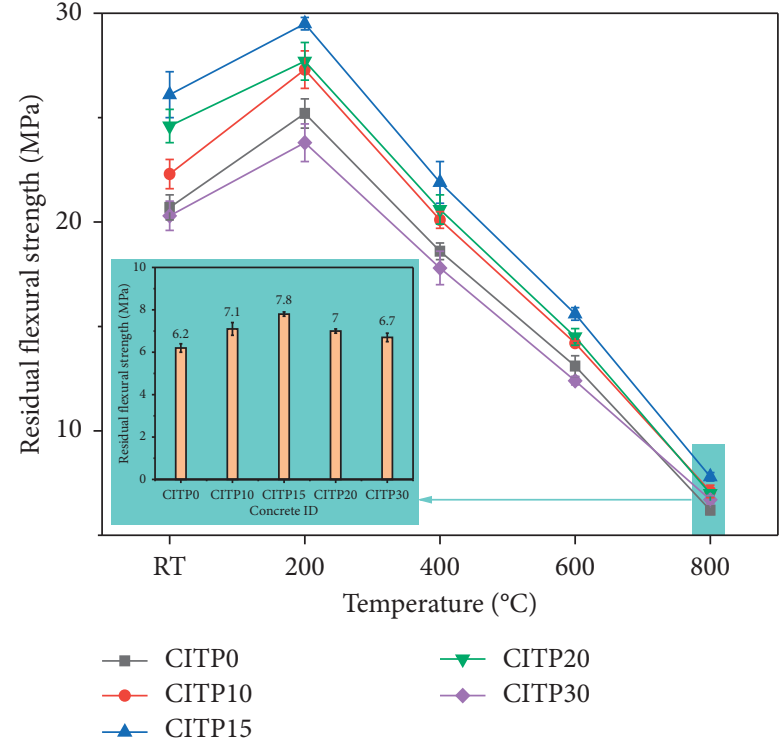

(b)

FIGURE 4: Residual strength of concrete: (a) residual compressive and (b) residual flexural strength.

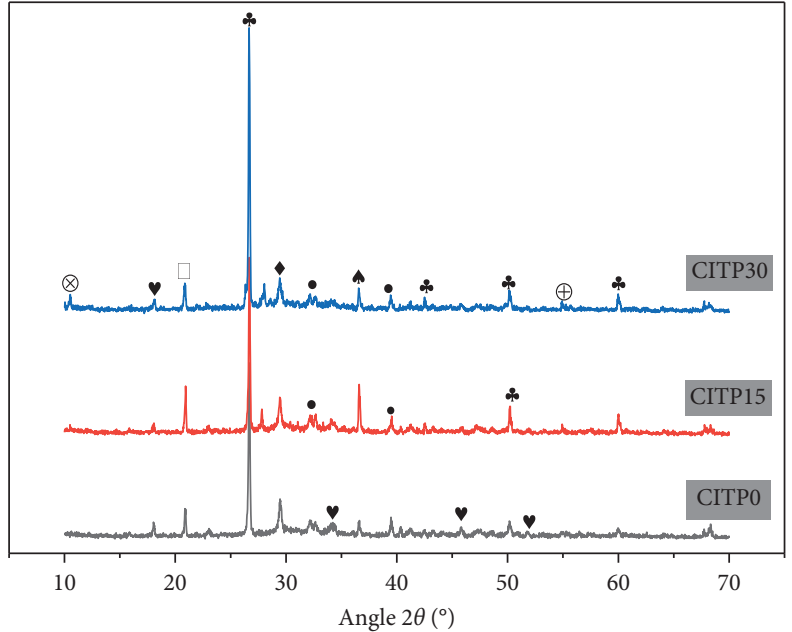

- $\mathrm{Ca}(\mathrm{OH})_{2}$

* $\mathrm{SiO}_{2}$ (Quartz)

- $\mathrm{CaCO}_{3}$ (Calcite)

^ Magnetite;
- $\mathrm{C}_{\mathrm{n}} \mathrm{S}$ (Alite, Belite)

$\otimes \mathrm{CACH}$

$\oplus \mathrm{CaO}$ (Lime)

$\square$ Ettringite

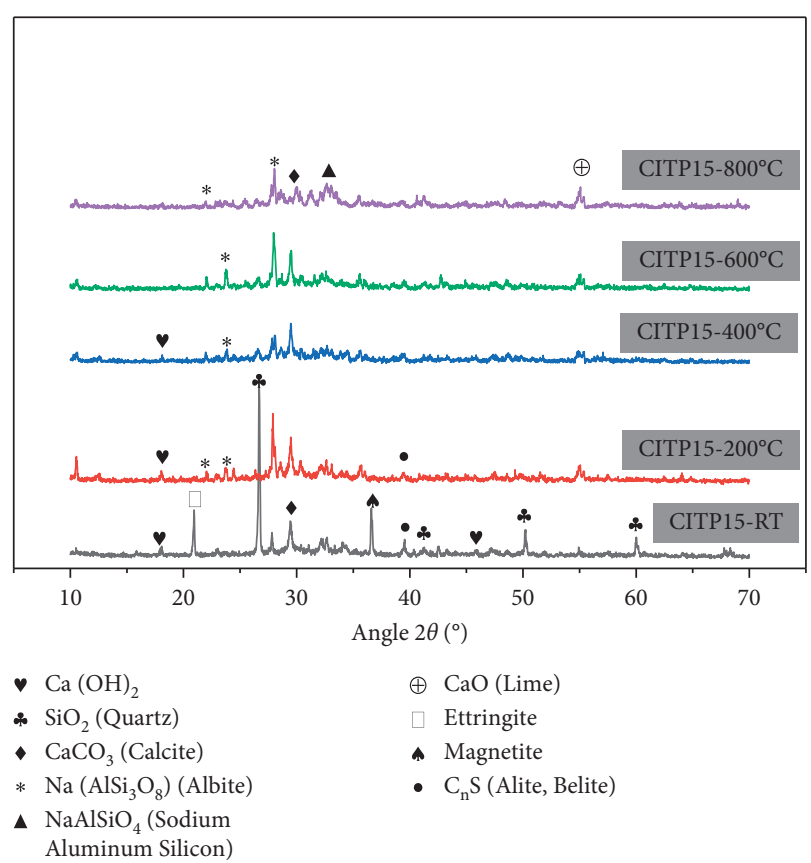

(b)

(a)

FIGURE 5: XRD patterns of concrete: (a) the reference sample CITP0, CITP15, and CITP30 at RT and (b) the sample CITP15 after exposure to high temperatures.

sample was slightly higher compared to CITP30; it indicated that the addition of ITP was involved in the chemical reaction. A similar conclusion has been confirmed by the earlier work [19], which indicated that if ITP does not participate in the chemical reaction; the sample incorporating ITP will show higher $\mathrm{CH}$ content than that of the sample without ITP. This result further demonstrated that the ITP participated in the reaction and some $\mathrm{CH}$ was consumed.

As evident from Figure 6(b), the first peak (\#1) of sample CITP $15-200^{\circ} \mathrm{C}$ is lower than that of the sample CITP15-RT. Note that, the water content further decreased with temperature and almost disappeared at $800^{\circ} \mathrm{C}$. The content of $\mathrm{CH}$ (\#3) showed a significant decrease at $400^{\circ} \mathrm{C}$ and 


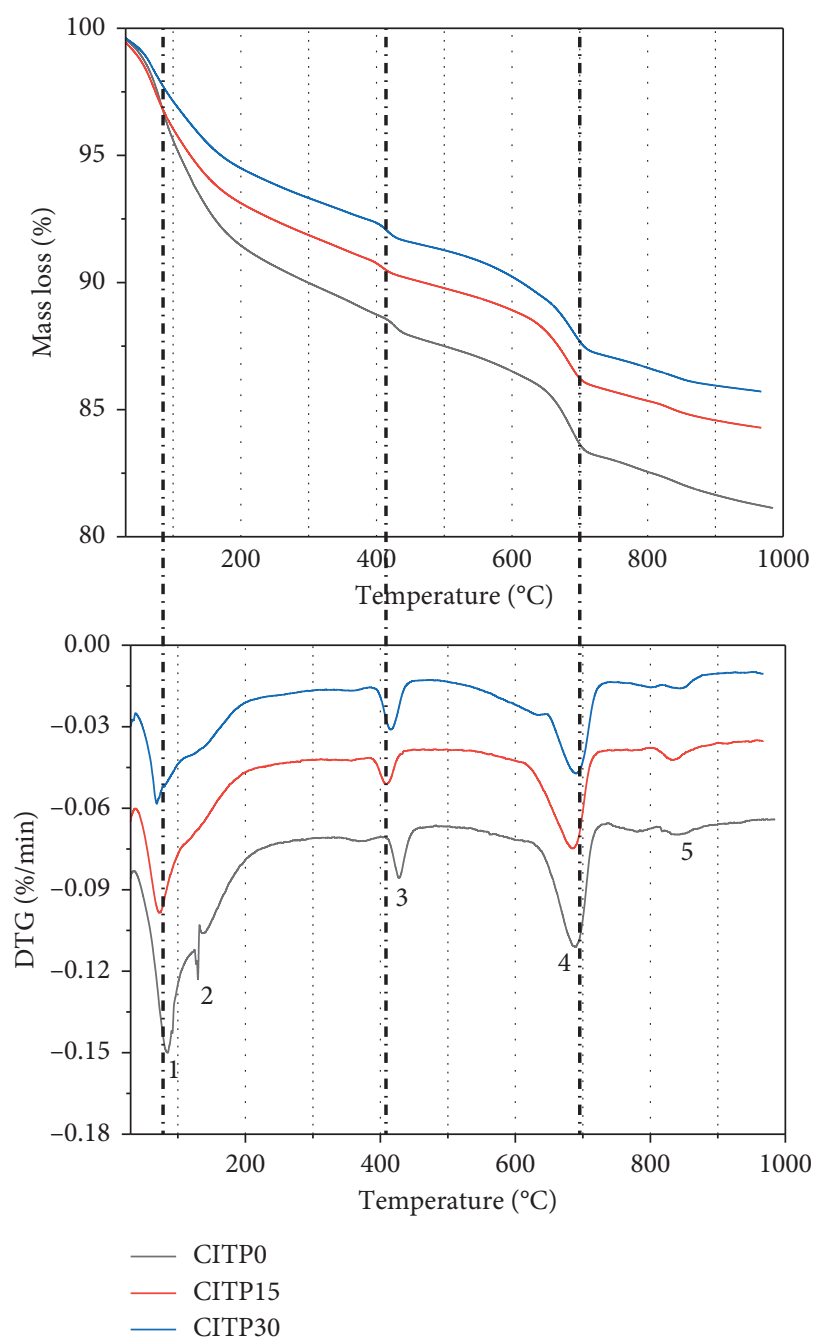

(a)

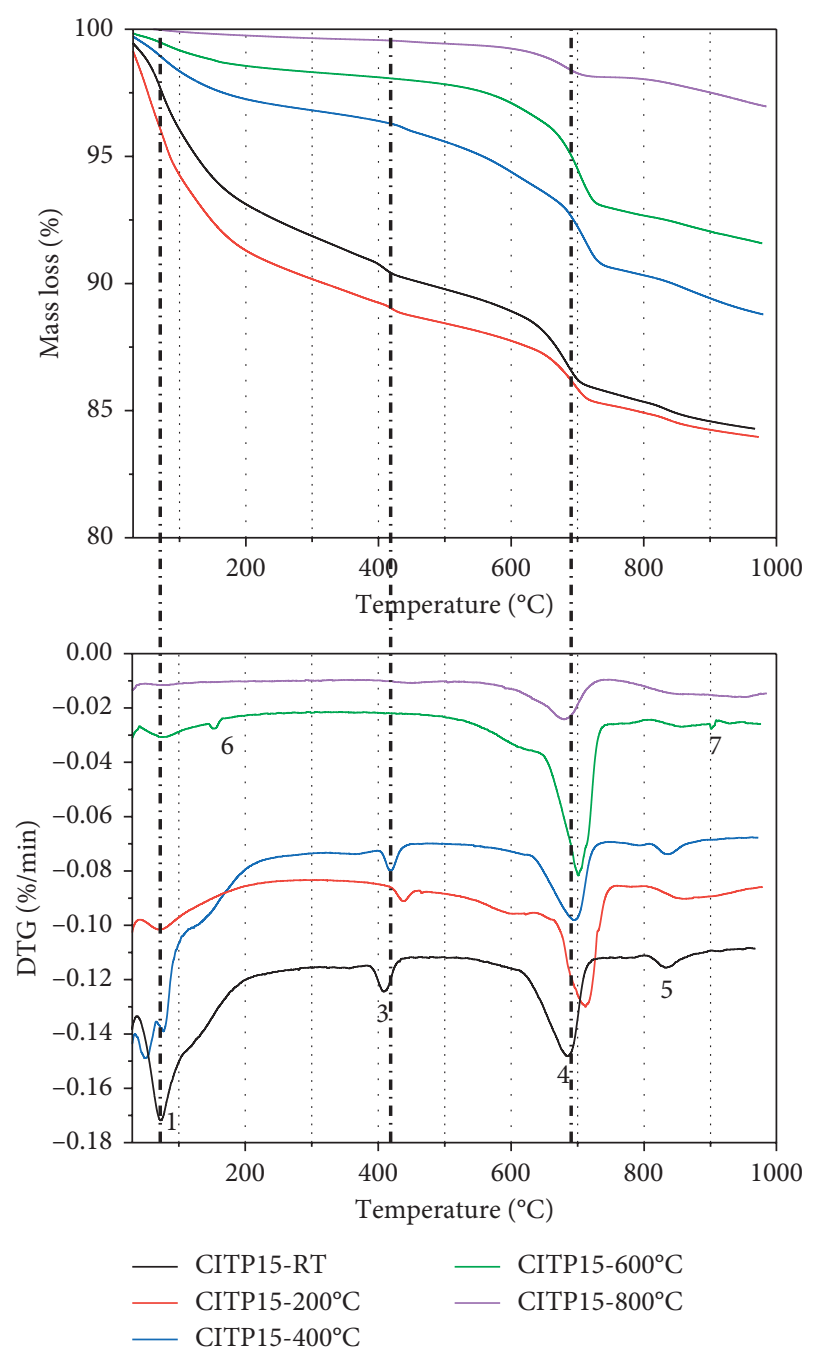

(b)

FIgURe 6: DTA curves and mass loss of concrete: (a) the reference sample CITP0, CITP15, and CITP30 at RT; (b) the CITP15 exposed to high temperatures.

disappeared at temperatures above $600^{\circ} \mathrm{C}$. This was mainly because the $\mathrm{CH}$ crystal began to decompose over a temperature range between $350^{\circ} \mathrm{C}$ and $600^{\circ} \mathrm{C}$ [37]. These results were consistent with the above-discussed XRD results (Figure 5).

3.7. FTIR. The band around $3576.21 \mathrm{~cm}^{-1}$ corresponds to the vibration of [O-H] in $\mathrm{CH}$ [30], as seen in Figure 7(a). The bands at $3380.04 \mathrm{~cm}^{-1}$ and $1617.37 \mathrm{~cm}^{-1}$ were attributed to the $[\mathrm{O}-\mathrm{H}]$ stretching vibration of structural water and the vibration of $[\mathrm{H}-$ $\mathrm{O}-\mathrm{H}]$ of interlayer water in hydration products, respectively [29]. The bands of $\left[\mathrm{SiO}_{4}\right]$ around $968.71 \mathrm{~cm}^{-1}$ and $871.55 \mathrm{~cm}^{-1}$ confirmed that some hydration products were formed in UHPC incorporating ITP [30]. It suggested that the ITP particles that participated in the chemical reaction and generated the additional hydration products.

For the CITP15 sample at RT, the band can be observed at about $3380.04 \mathrm{~cm}^{-1}$, while it was not detected in sample CITP15 at high temperatures (Figure $7(\mathrm{~b})$ ). This indicated that the decomposition of AFt and some C-S-H gel in concrete after exposure to elevated temperatures. Besides, the bands of $\left[\mathrm{SiO}_{4}\right]$ at $968.71 \mathrm{~cm}^{-1}$ and $871.55 \mathrm{~cm}^{-1}$ in sample CITP15 became weaker. This also confirmed that the hydration products of concrete gradually disappeared.

3.8. Microstructure Observation. As presented in Figure 8, the CTIP15 sample achieves a remarkably dense microstructure at RT. Several voids, microcracks, and unhydrated cement particles could be found in the CITP0 sample (Figure 8(a)) and CITP30 (Figure 8(c)). The fine ITP particles with high specific surface area (see Section 2.1) and adsorbed a lot of free water, which resulted in an increase in the amount of unhydrated cement in the CITP30 sample. On further magnification, some needle-like AFt could be observed in the reference sample (Figure $8(d)$ ). The needle-like crystals overlapped each other and formed a network structure (Figure 8(e)). This could at least partially explain the CITP15 sample demonstrating the highest compressive 


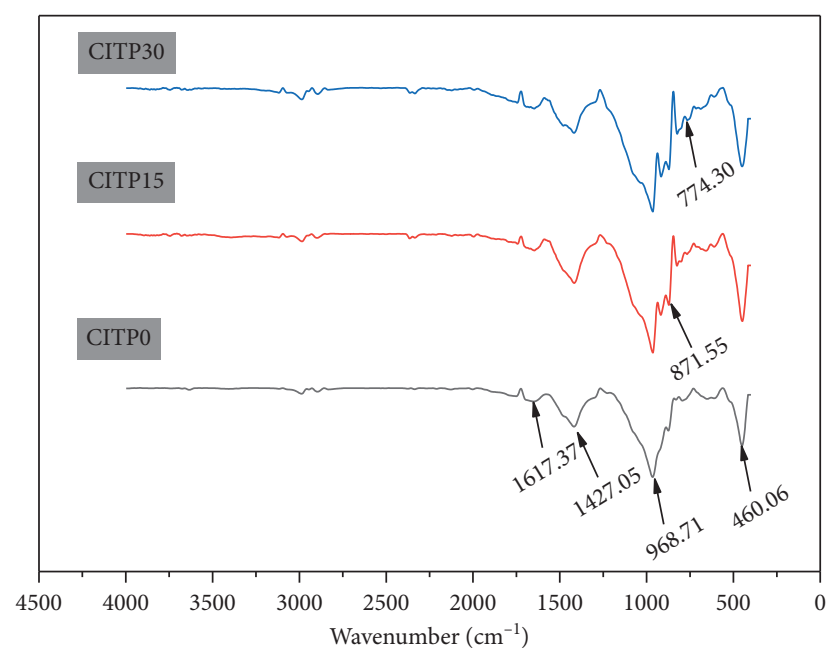

(a)

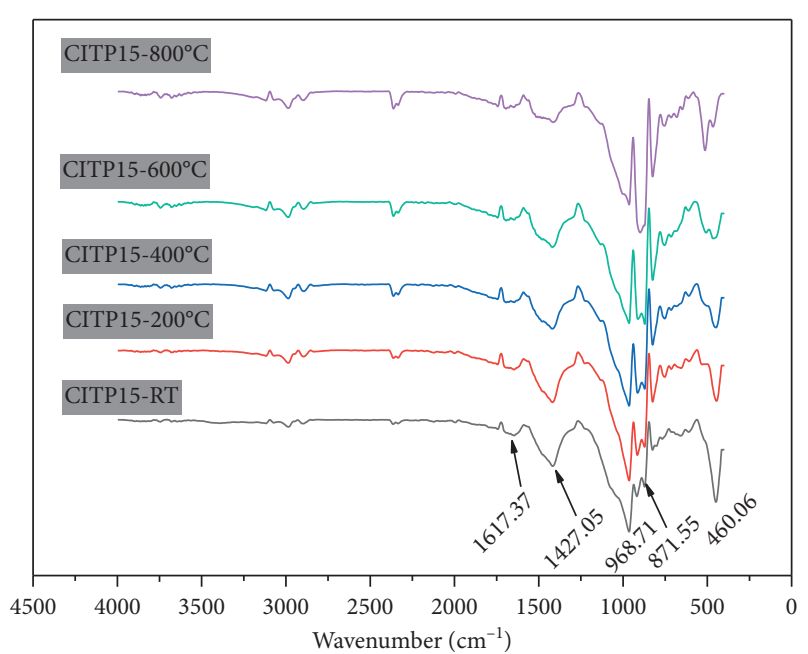

(b)

FIGURE 7: FTIR spectrum of concrete: (a) the reference sample CITP0, CITP15, and CITP30 at RT; (b) the sample CITP15 after exposure to high temperatures.

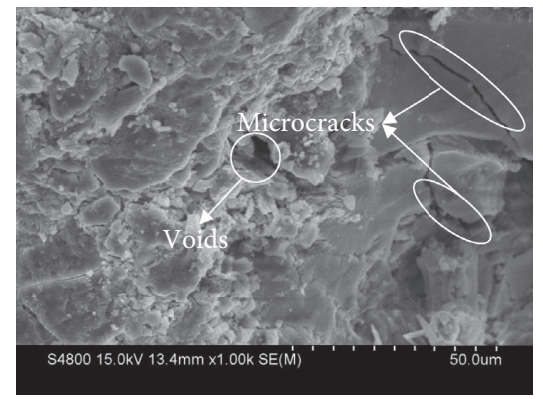

(a)

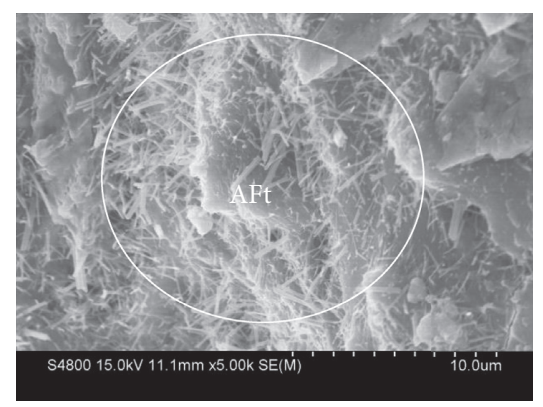

(d)

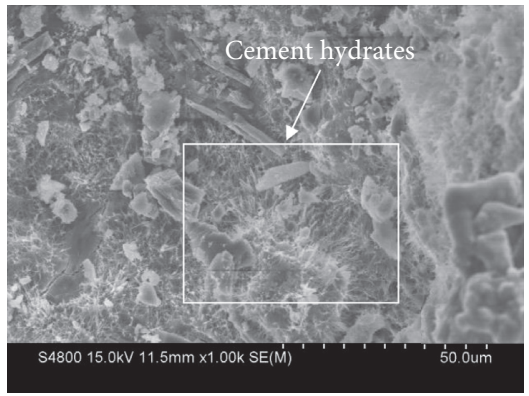

(b)

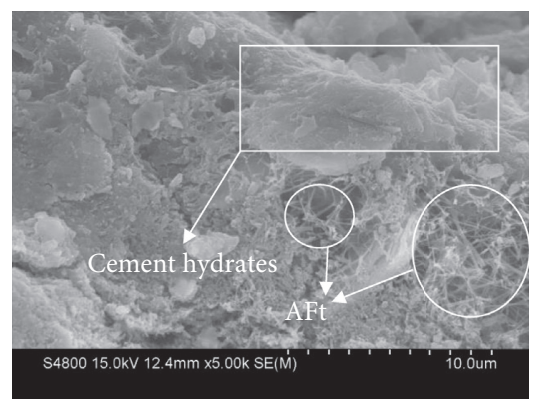

(e)

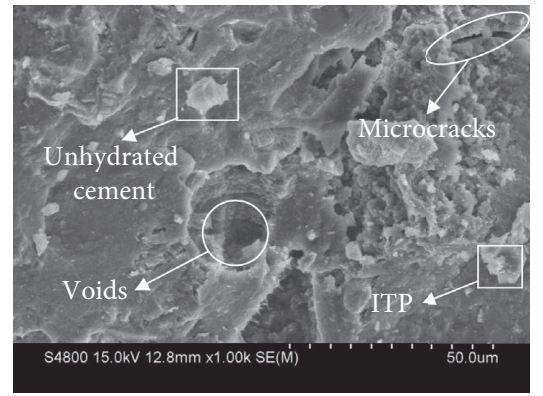

(c)

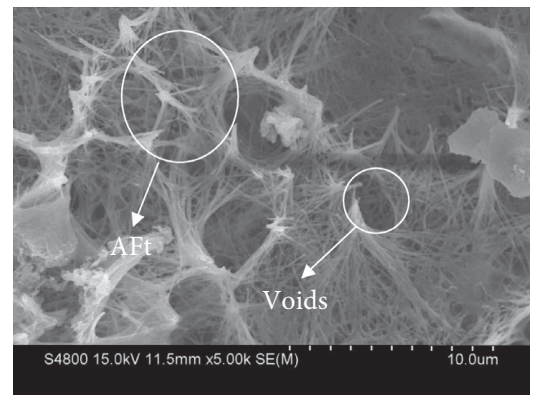

(f)

Figure 8: Microstructure of concrete: (a) sample CIP0, (b) CIP15, and (c) CIP30 with magnification of $\times 1,000$; (d) sample CIP0, (e) CIP15, and (f) CIP30 with magnification of $\times 5,000$.

strength (Figure 2). Interestingly, several voids were observed in the CITP30 sample and some voids were filled with cement hydrates (Figure $8(f)$ ). This was mainly due to the surface of the ITP particle was not smooth and linked with the cement hydrates.

Numerous micropores and microcracks were found in UHPC specimens at high temperatures (Figure 9). Besides, the hydration products gradually disappeared, unlike the CITP15 sample under RT that had several needle-like AFt (Figure 9(a)). The microstructure of the CITP15 sample at $200^{\circ} \mathrm{C}$ (Figure 9(b)) showed a denser structure compared with the sample at RT (Figure 9(a)). This was mainly because the hydration products were generated at $200^{\circ} \mathrm{C}$ and filled the pores $[8,14]$. Up to $800^{\circ} \mathrm{C}$, the CITP 15 sample presented a relatively complete structure and had a small number of microcracks (Figure 9(e)), which helped to release the thermal stress and improved the high-temperature resistance of 


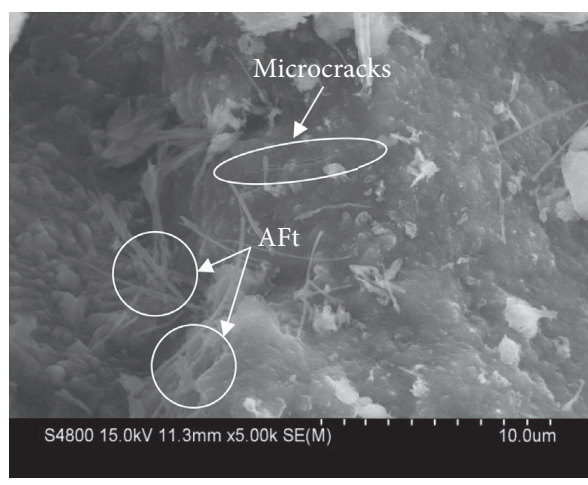

(a)

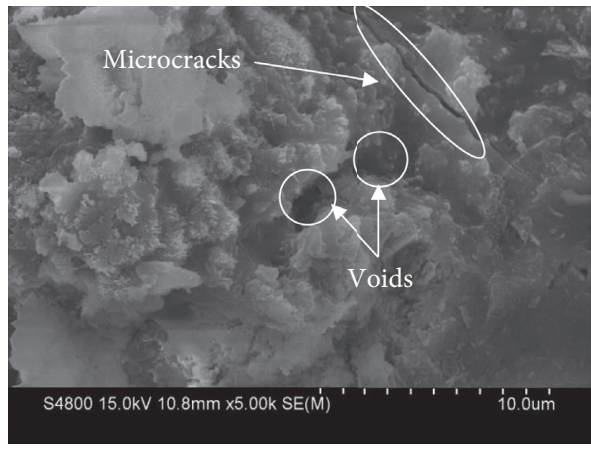

(c)

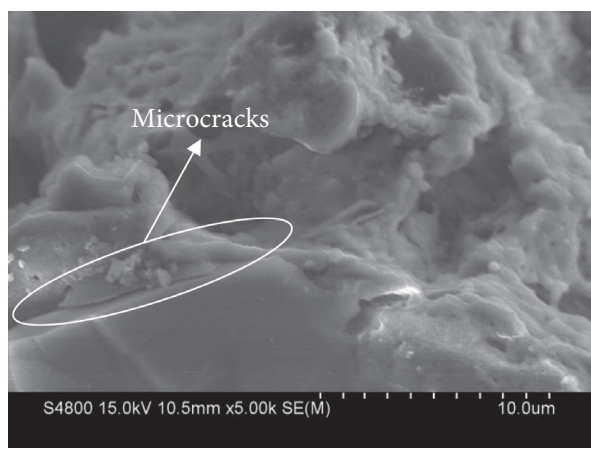

(e)

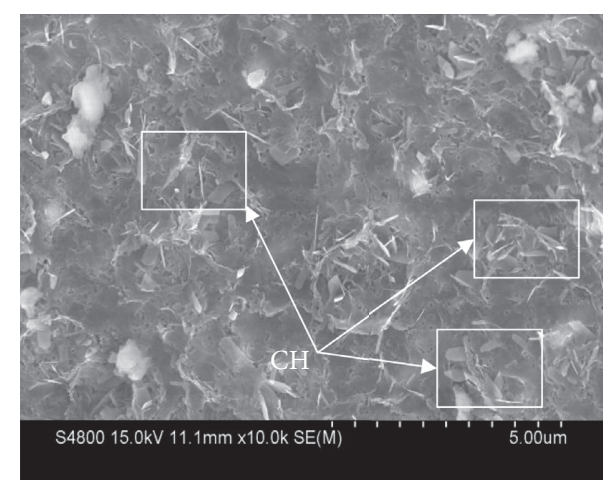

(b)

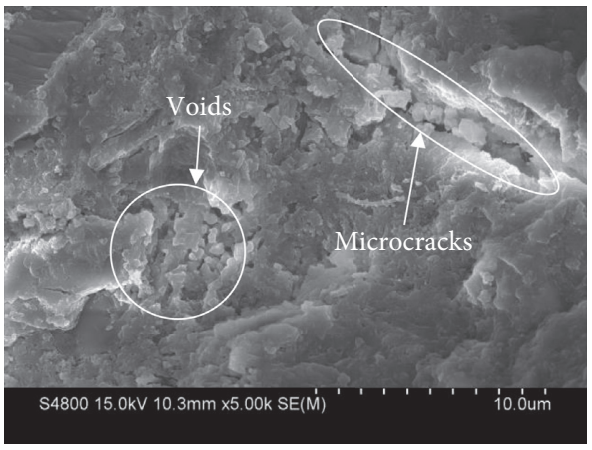

(d)

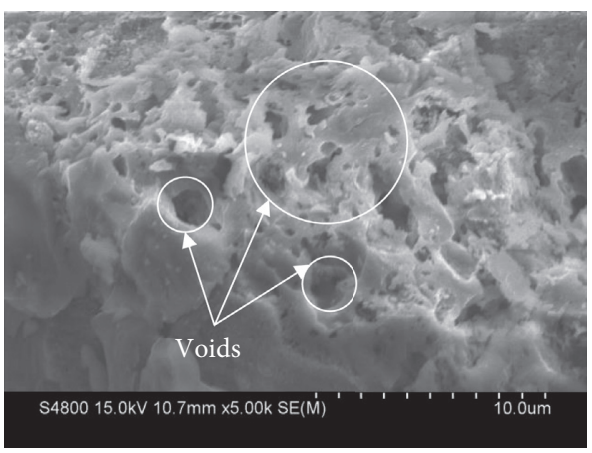

(f)

Figure 9: Microstructure of CITP15 (a) at room temperature; (b) at $200^{\circ} \mathrm{C}$; (c) at $400^{\circ} \mathrm{C}$; (d) at $600^{\circ} \mathrm{C}$; (e) at $800^{\circ} \mathrm{C}$; and (f) the sample CITP30 at $800^{\circ} \mathrm{C}$.

concrete. Some micropores/cracks could be observed in the CITP30 sample at $800^{\circ} \mathrm{C}$ (Figure 9(f)), which improved the high-temperature resistance of concrete [8]. Therefore, the concrete containing 30\% ITP maintained $39.7 \%$ of its original strength at $800^{\circ} \mathrm{C}$, higher than that of the concrete without ITP (Figure 4).

\section{Conclusions}

Mechanical behavior and microstructural properties of UHPC containing ITP at high temperatures were investigated in this study. Residual strength and bound water content of UHPC mortars were discussed. Also, their microscopic investigation was studied by XRD, TGA, FTIR, and SEM techniques. The main findings can be concluded as follows:
(1) The addition of ITP particles has accelerated the hydration of cement and the filling effect of ITP refined the pore structure, which contributed to the strength development of UHPC mortars. As a result, the concrete with the addition of 15\% ITP achieved the highest compressive strength of $148.8 \mathrm{MPa}$ at 28 days.

(2) The addition of ITP has postponed the spalling of UHPC mortars at high temperatures, because the number of micropores, microvoids, and microcracks has increased, which helped to release the accumulated vapor pressure, thereby improving the residual strength of concrete.

(3) Some water released by the hydration products can be used to rehydrate the unhydrated cement particles, thereby slightly enhanced the strength of the 
UHPC mortars at $200^{\circ} \mathrm{C}$. Amorphous phases and microstructure results demonstrated that the ITP particles have participated in the chemical reaction and some $\mathrm{CH}$ has consumed.

(4) The outstanding mechanical strength of UHPC mortars due to the addition of ITP particles has alleviated the microstructure degradation caused by free water evaporation, thereby improving the hightemperature resistance of concrete.

\section{Data Availability}

The residual strength data used to support the findings of this study have not been made available because another work, we are doing, has not yet been published.

\section{Conflicts of Interest}

The authors declare that there are no conflicts of interest regarding the publication of this paper.

\section{Acknowledgments}

This work was supported by the Natural Science Foundation of Qinghai Province (No. 2020-ZJ-736).

\section{References}

[1] M. S. Morsy, Y. A. Al-Salloum, H. Abbas, and S. H. Alsayed, "Behavior of blended cement mortars containing nanometakaolin at elevated temperatures," Construction and Building Materials, vol. 35, pp. 900-905, 2012.

[2] W. Wang, C. Lu, Y. Li, and Q. Li, "An investigation on thermal conductivity of fly ash concrete after elevated temperature exposure," Construction and Building Materials, vol. 148, pp. 148-154, 2017.

[3] X. Liang, C. Wu, Y. Yang, and Z. Li, "Experimental study on ultra-high performance concrete with high fire resistance under simultaneous effect of elevated temperature and impact loading," Cement and Concrete Composites, vol. 98, pp. 29-38, 2019.

[4] F. Lo Monte, R. Felicetti, and M. J. Miah, "The influence of pore pressure on fracture behaviour of normal-strength and high-performance concretes at high temperature," Cement and Concrete Composites, vol. 104, 2019.

[5] A. M. Rashad, "Potential use of phosphogypsum in alkaliactivated fly ash under the effects of elevated temperatures and thermal shock cycles," Journal of Cleaner Production, vol. 87, pp. 717-725, 2015.

[6] X. Liang, C. Wu, Y. Yang, C. Wu, and Z. Li, "Coupled effect of temperature and impact loading on tensile strength of ultrahigh performance fibre reinforced concrete," Composite Structures, vol. 229, 2019.

[7] Z. Mo, R. Wang, and X. Gao, "Hydration and mechanical properties of UHPC matrix containing limestone and different levels of metakaolin," Construction and Building Materials, vol. 256, Article ID 119454, 2020.

[8] N. K. Lee, K. T. Koh, S. H. Park, and G. S. Ryu, "Microstructural investigation of calcium aluminate cement-based ultra-high performance concrete (UHPC) exposed to high temperatures," Cement and Concrete Research, vol. 102, pp. 109-118, 2017.
[9] T. Xie, C. Fang, M. S. Mohamad Ali, and P. Visintin, "Characterizations of autogenous and drying shrinkage of ultra-high performance concrete (UHPC): an experimental study," Cement and Concrete Composites, vol. 91, pp. 156-173, 2018.

[10] C. Fang, M. Ali, T. Xie, P. Visintin, and A. H. Sheikh, "The influence of steel fibre properties on the shrinkage of ultrahigh performance fibre reinforced concrete," Construction and Building Materials, vol. 242, 2020.

[11] O. Karahan, "Transport properties of high volume fly ash or slag concrete exposed to high temperature," Construction and Building Materials, vol. 152, pp. 898-906, 2017.

[12] K. M. Anwar Hossain, "High strength blended cement concrete incorporating volcanic ash: performance at high temperatures," Cement and Concrete Composites, vol. 28, no. 6, pp. 535-545, 2006.

[13] O. Burciaga-Díaz and J. I. Escalante-García, "Comparative performance of alkali activated slag/metakaolin cement pastes exposed to high temperatures," Cement and Concrete Composites, vol. 84, pp. 157-166, 2017.

[14] R. Manjunath, M. C. Narasimhan, and K. M. Umesha, "Studies on high performance alkali activated slag concrete mixes subjected to aggressive environments and sustained elevated temperatures," Construction and Building Materials, vol. 229, 2019.

[15] H. K. Shehab El-Din, A. S. Eisa, B. H. Abdel Aziz, and A. Ibrahim, "Mechanical performance of high strength concrete made from high volume of Metakaolin and hybrid fibers," Construction and Building Materials, vol. 140, pp. 203-209, 2017.

[16] D. Shen, Y. Jiao, J. Kang, Z. Feng, and Y. Shen, "Influence of ground granulated blast furnace slag on early-age cracking potential of internally cured high performance concrete," Construction and Building Materials, vol. 233, 2020.

[17] W. G. Valencia Saavedra and R. Mejía de Gutiérrez, "Performance of geopolymer concrete composed of fly ash after exposure to elevated temperatures," Construction and Building Materials, vol. 154, pp. 229-235, 2017.

[18] P. Zhu, S. Brunner, S. Zhao et al., "Study of physical properties and microstructure of aerogel-cement mortars for improving the fire safety of high-performance concrete linings in tunnels," Cement and Concrete Composites, vol. 104, 2019.

[19] F. Han, A. Luo, J. Liu, and Z. Zhang, "Properties of highvolume iron tailing powder concrete under different curing conditions," Construction and Building Materials, vol. 241, 2020.

[20] F. Han, L. Li, S. Song, and J. Liu, "Early-age hydration characteristics of composite binder containing iron tailing powder," Powder Technology, vol. 315, pp. 322-331, 2017.

[21] W. C. Fontes, J. M. Franco de Carvalho, L. C. R. Andrade, A. M. Segadães, and R. A. F. Peixoto, "Assessment of the use potential of iron ore tailings in the manufacture of ceramic tiles: from tailings-dams to "brown porcelain," Construction and Building Materials, vol. 206, pp. 111-121, 2019.

[22] G. Yao, Q. Wang, Z. Wang, J. Wang, and X. Lyu, "Activation of hydration properties of iron ore tailings and their application as supplementary cementitious materials in cement," Powder Technology, vol. 360, pp. 863-871, 2020.

[23] GB175-2007, Common Portland Cement, Chinese National Standard, Beijing, China, 2007, in Chinese.

[24] T. Zhang, Q. Yu, J. Wei, P. Zhang, and P. Chen, “A gap-graded particle size distribution for blended cements: analytical approach and experimental validation," Powder Technology, vol. 214, no. 2, pp. 259-268, 2011. 
[25] GB/T17671-1999, Method of Testing Cements-Determination of Strength, BSI Standards, London, UK, 1999, in Chinese.

[26] F. Han, S. Song, J. Liu, and S. Huang, "Properties of steamcured precast concrete containing iron tailing powder," Powder Technology, vol. 345, pp. 292-299, 2019.

[27] R. Abaeian, H. P. Behbahani, and S. J. Moslem, "Effects of high temperatures on mechanical behavior of high strength concrete reinforced with high performance synthetic macro polypropylene (HPP) fibres," Construction and Building Materials, vol. 165, pp. 631-638, 2018.

[28] D. Lu, Z. Tang, L. Zhang et al., "Effects of combined usage of supplementary cementitious materials on the thermal properties and microstructure of high-performance concrete at high temperatures," Materials, vol. 13, no. 8, 2020.

[29] X. Li, N. Zhang, J. Yuan et al., "Preparation and microstructural characterization of a novel 3D printable building material composed of copper tailings and iron tailings," Construction and Building Materials, vol. 249, 2020.

[30] F. Han, Y. Zhou, and Z. Zhang, "Effect of gypsum on the properties of composite binder containing high-volume slag and iron tailing powder," Construction and Building Materials, vol. 252, 2020.

[31] T. G. G. Molay, M. N. L. Leroy, T. Fidele, H. G. Franck, and N. J.-M. Bienvenu, "Mechanical and physical performances of concretes made from crushed sands of different geological nature subjected to high temperatures," Engineering Science and Technology, an International Journal, vol. 22, no. 4, pp. 1116-1124, 2019.

[32] D. Lu, J. Zhong, B. Yan et al., "Effects of curing conditions on the mechnical and microstructural properties of ultra-highperformance concrete (UHPC) incorporating iron tailing powder," Materials, vol. 14, no. 1, 2021.

[33] S. Pourchet, L. Regnaud, J. P. Perez, and A. Nonat, "Early C3A hydration in the presence of different kinds of calcium sulfate," Cement and Concrete Research, vol. 39, no. 11, pp. 989-996, 2009.

[34] L. Luo, K. Li, W. Fu, C. Liu, and S. Yang, "Preparation, characteristics and mechanisms of the composite sintered bricks produced from shale, sewage sludge, coal gangue powder and iron ore tailings," Construction and Building Materials, vol. 232, 2020.

[35] K. Do Carmo e Silva Defáveri, L. F. Dos Santos, J. M. Franco de Carvalho, R. A. F. Peixoto, and G. J. Brigolini, "Iron ore tailing-based geopolymer containing glass wool residue: a study of mechanical and microstructural properties," Construction and Building Materials, vol. 220, pp. 375-385, 2019.

[36] J. Yang, G.-F. Peng, J. Zhao, and G.-S. Shui, "On the explosive spalling behavior of ultra-high performance concrete with and without coarse aggregate exposed to high temperature," Construction and Building Materials, vol. 226, pp. 932-944, 2019.

[37] B. Zhang, "Effects of moisture evaporation (weight loss) on fracture properties of high performance concrete subjected to high temperatures," Fire Safety Journal, vol. 46, no. 8, pp. 543-549, 2011. 